neurofibromatosis type 2 was confirmed by a gadolinium MRI in a 14year-old girl who presented with flaccid weakness and wasting of the left upper limb and EMG evidence of brachial plexopathy (Millichap JG, Gomez MR. Ped Neur Briefs July 1990; 4 : 50-51). The standard MRI was inconclusive whereas the gadolinium imaging revealed enlargement of neural formina C 5-6 on the left side and evidence of a plexiform neurofibroma. Examination of the skin showed depigmented and cafeau-lait patches, helpful in the diagnosis in this case.

\title{
CRITICAL-ILLNESS POLYNEUROPATHY
}

A review of the neurological complications of sepsis from the University of Western Ontario, London, and Queen's University, Kingston, Ontario, Canada, draws attention to "critical-illness polyneuropathy" as a cause of difficulty in weaning from the ventilator. Patients with major medical, surgical, or traumatic illnesses who are in the recovery phase of septic encephalopathy may develop respiratory difficulties as an early sign of polyneuropathy. Electrophysiological studies, showing reduction of diaphragmatic action potential and denervation of chest wall muscles, may be diagnostic of the neuropathy before weakness of limbs and areflexia develop. In contrast to the central nervous system, damage to the peripheral nervous system is more severe and sometimes persistent in the septic syndrome. (Bolton CF et al. The neurological complications of sepsis. Ann Neurol Jan 1993; 33: 94-100). (Correspondence: Dr Bolton, Victoria Hospital, 375 South Street, London, Ontario N6A 4G5, Canada).

COMMENT. In addition to encephalopathy and polyneuropathy, patients with sepsis may develop myositis or myopathy and an elevated CPK. The EEG and EMG are sensitive indicators of these complications of the septic syndrome.

\section{CEREBROVASCULAR DISEASE}

\section{ASYMPTOMATIC ANEURYSMS AND HIV INFECTION}

Aneurysms of major cerebral arteries in two children, aged 11 and 12 years, infected with human immunodeficiency virus from blood transfusions are reported from the National Institutes of Health, Bethesda, MD, and Georgetown University Hospital, Washington, DC. The incidence among 250 children treated and monitored with MRI was 0.8 percent. The aneurysms developed and progressed during therapy and follow-up but were asymptomatic. The role of HIV infection in these lesions was undetermined. (Husson RN et al. Cerebral artery aneurysms in children infected with human immunodeficiency virus. LPediatr Dec 1992; 121: 927-930). (Reprints: Philip A 